\title{
Correlates of early reading skills among pre-school children in Iran
}

\begin{abstract}
This study was carried out to examine some of the factors influencing early reading skills among pre-school children in selected nursery schools in tehran, Iran. Descriptive research design of the correlation type was used. A self-developed questionnaire was administered to identify and measure reading skills and factors influencing their development. Randomly selected 300 teachers and parents from 10 purposively selected private and public nursery schools participated in the study. The results obtained revealed significant factors associated with early reading skills. The findings also indicated the significant correlation between learning environment in the classroom and early reading skills $(\mathrm{r}=0.29 ; \mathrm{p}<0.05)$, the significant correlation between home learning environment and early reading skills $(\mathrm{r}=0.29 ; \mathrm{p}<0.05)$, and the significant correlation between peer group influence and early reading skills of preschool age children $(\mathrm{r}=0.22 ; \mathrm{p}<0.05)$. The study concluded that conducive learning environment in school and at home are important factors that can significantly improve development of reading skills at early childhood period. It was also established that children with higher abilities can positively challenge and influence another child's skills development. Based on the above findings, the study recommended that educators and parents should always remember to take care of conducive learning environment for pre-school children by providing stimulating atmosphere that enhances all-round development. Peer group influence should be also considered as it may play a positive role in child's development of early reading skills.
\end{abstract}

Keywords: early years reading skills, stimulating learning environment, peer group influence, Iran
Volume 3 Issue $6-2018$

\author{
Morteza Alibakhshi Kenari \\ Martyr Beheshti University of Medical Sciences and Health \\ Services, Tehran, Iran
}

\begin{abstract}
Correspondence: Morteza alibakhshi kenari, Martyr Beheshti University of Medical Sciences and Health Services, Tehran, Iran, Email Morteza.alebakhshikenari@gmail.com
\end{abstract}

Received: October 23, 2018| Published: November 27, 2018

\section{Introduction}

The critical importance of the first few years of children's life in shaping their future achievements is widely recognised. Although research in child development across different disciplines has been largely independent, important common findings are emerging. Many researchers established the fact that skill development is a dynamic process which builds on earlier skill levels. ${ }^{1}$ This process depends not only on genetics but is also built on experiences beginning at early childhood period of development. ${ }^{2-4}$

Bodrova $^{5}$ remarked that educators in countries across the globe face the same pressure to start exposing children to academic skills at a progressively younger age. This pressure is largely caused by the concerns about children not being ready for school as well as concerns about children falling behind in their later learning outcomes. So, there must be certain prerequisites acquired by the child before formal schooling, and one of those prerequisites are reading skills.

During language development, children learn skills that are important to the development of literacy (ability to read and write). At early childhood stage of development, literacy is characterised as emergent literacy, which means that children just start learning how to understand language to express ideas and feelings, communicate with others, appreciate and enjoy prints, identify logos and streets signs, recognize some letters of the alphabet. Gradually, children combine what they know about speaking and listening with what they know about print and become ready to read. Therefore, the experiences with talking and listening gained during early years prepare children to learn to read. This means that early years care educational institutions together with the family should provide stimulating environment for children to be able to have maximum experience in language use and the development of pre-reading and reading skills. It also means that children who enter school with weaker verbal abilities are much more likely to experience difficulties learning literacy.

Early childhood period of development is the ideal time for caregivers and parents to foster and build early reading skills for a strong start of formal schooling. The ability to read fluently is a key to academic success during formal education and, therefore, development of reading skills must be regarded as an essential component of early childhood curriculum.

To be able to provide effective learning experiences in early childhood classroom, it is necessary to understand the complex dynamic interactions between the development of reading skills and the factors that may foster their quality. Numerous studies on early education have demonstrated that it is important to consider certain external conditions, which can promote or discourage the development of the child. ${ }^{6-8}$ According to Ashiabi ${ }^{9}$ classroom environment communicates to children what is expected of them. In early year's classroom, the use of learning centers is a key to ensuring the adequate output from children. Children's learning is as well enhanced when their families are involved and make necessary provisions for deferent kinds of learning experiences including verbal communication. ${ }^{10}$ When children are actively engaged, they have the opportunity to practice existing abilities, perfect emerging skills and acquire new competences. ${ }^{11,12}$ 
With the ever increasing pursuit for improved living conditions, increased income generation and other demands placed on Nigerian parents, not all households have been able to establish a reasonably conducive and stimulating learning environment at home. The result has been the near total reliance on the opportunities provided in schools and the inability to fully harness the potentials of the child. In addressing this anomaly, Ossai-Onah ${ }^{13}$ advocates for a re-orientation for parents towards attaching greater priority to creating a conducive environment for early learning in the home in view of its prime importance and contribution to the acquisition of quality lifelong learning skills.

There are varying degrees to which the Nigerian families in $21 \mathrm{st}$ century nurture the sustenance and development of pre-reading and reading skills in children during their early years. The determining factors in this regard among others could include individual parents educational and economic status, parenting orientation and priorities. For instance, parents who have the financial wherewithal are prone to make a home setting which stimulates early learning. On the other hand, parents in the low income class even if uneducated and if interested in the betterment of the future of their children, could devote greater attention, instil a disciplined approach to academic pursuits and encourage a home environment that moderates distractions and encourages private and child centered reading culture, especially in the early childhood years. ${ }^{14}$

It is important to note the gender perspective to this challenge. While more mothers are noted to devote some time in building the reading skills of their children, less number of fathers are known to be willing and committed to sparing some time in this venture. ${ }^{15}$ Along the same line, while more girl children will be encouraged to assist in domestic chores or spend time on their assignments or in reading, more often than not, it is permissible for the boy-child to engage in games at home or within the neighbourhood and later be coerced into sparing a little moment to read or face homework given in school.

In this study we hypothesised that there could be a certain correlation between levels of reading skills and learning environment at school and at home as well as a correlation between children's reading skills and peer group influence.

\section{Methodology}

The study employed the use of the descriptive survey research design to identify and assess reading skills of the preschoolers and factors stimulating those skills. The target population comprised all teachers and parents of pre-school children in Tehran, Iran.

A total number of 300 teachers and parents were involved in the study. They were randomly selected from 10 purposively selected private and public pre-school institutions in the State.

A self-developed questionnaire based on literature review was used to collect data on research variables. It was divided into 3 sections. Section "A" dealt with the personal information of the respondents such as gender, marital status, educational attainment, family size and occupation while items in sections " $\mathrm{B}$ " and " $\mathrm{C}$ " collected information on assessment of early reading skills and identified factors influencing reading skills. Four-point Likert-type scale was used to measure the responses as Strongly Agree (SA), Agree (A), Disagree (D) and Strongly Disagree (SD). The instrument was validated by experts and the test re-test technique determined the reliability coefficient of 0.78 . These permitted to conclude that the questionnaire was suitable for the study. Both descriptive and inferential statistics were employed in analysing the data. Pearson product moment correlation coefficient was used to test the hypotheses generated for the study at 0.05 level of significance.

\section{Results}

Research Hypothesis One: There is no significant correlation between learning environment in the classroom and early reading skills.

Table 1 explains the correlation between learning environment in the classroom and early reading skills. The calculated $r$-value of 0.33 is positive and is greater than the critical $(r=0.195)$ at 0.05 level of significance. Since the calculated value is greater that the critical value, then the relationship between the two variables is significant and therefore, the stated hypotheses is not accepted. This means that there is a significant correlation between learning environment in the classroom and early reading skills of children participated in the study as reported by respondents.

Table I Correlation between learning environment in the classroom and early reading skills

\begin{tabular}{lllll}
\hline Variables & Mean & SD & r-cal & r-critical \\
\hline Classroom Environment & 13.02 & 3.12 & & \\
Reading skills & 13.75 & 3.1 & 0.33 & 0.195 \\
\hline
\end{tabular}

$p<0.05$

Research Hypothesis Two: There is no significant correlation between home learning environment and early reading skills.

From Table 2, the $r$-calculated $(r=0.29)$ is positive and is greater than the critical value $(\mathrm{r}=0.195)$ at 0.05 significant level. It demonstrates a positive relationship between home learning environment and early reading skills. That is, the more home provides learning opportunities for a child, the higher child's level of reading skills can be. Therefore, having that the calculated value is greater than the critical, it is concluded that the relationship between the two variables is significant. This implies that the postulated hypothesis is not accepted and there is a significant correlation between home learning environment and early reading skills of selected pre-school age children in Tehran.

Table 2 Correlation between home learning environment and early reading skills.

\begin{tabular}{lllll}
\hline Variables & Mean & SD & r-cal & r-critical \\
\hline Home environment & 13.22 & 2.96 & & \\
Reading skills & 13.75 & 3.1 & 0.29 & 0.195 \\
\hline
\end{tabular}

$\mathrm{p}<0.05$

Research Hypothesis Three: There is no significant correlation between peer group influence and early reading skills.

Table 3 shows the correlation between peer group influence and early reading skills. The $r$ - calculated $(r=0.22)$ is greater than the critical value $(r=0.195)$ at 0.05 level of significance. Therefore, there is a positive and significant relationship between peer group influence and early reading skills. This means that the hypothesis is not accepted and there is a significant correlation between peer group influence and early reading skills of pupils used in this study as reported by respondents. 
Table 3 Correlation between peer group influence and early reading skills

\begin{tabular}{lllll}
\hline Variables & Mean & SD & r-cal & r-critical \\
\hline Peer group influence & 11.99 & 2.8 & & \\
Reading skills & 13.75 & 3.1 & 0.22 & 0.195 \\
\hline
\end{tabular}

$\mathrm{p}<0.05$

\section{Discussion}

The analyses of findings in this study revealed that among many factors, conducive classroom and home environments as well as peer group play a significant role in the development of early reading skills among children in selected nursery schools in Tehran, Iran.

Significant relationship between classroom environment and children's learning achievements was reported by $\operatorname{Igwe}^{16}$ who confirmed that attractive and well-designed classroom helps preschoolers to be motivated and engaged in the work given to them and supports positive interactions. This findings as well goes with the view

of Haugland ${ }^{17}$ that 21 st Century early childhood classroom must provide opportunities to maximize early learning and to ensure quality of academic skills.

The study also established a significant correlation between home environment and the quality of reading skills. These results replicated the findings of other studies and underlined that achievement differences due to family background emerge very early in children's lives. It was in agreement with Bornstein \& Bradley, ${ }^{18}$ who found that financial and material resources of the family were associated especially with reading achievements of children. This finding also supported that of Anders et al..$^{19}$ and Burchinal et al. ${ }^{20}$ who argued that children from lower income and less educated families performed less in school than their counterparts from higher income, better educated and intact families.

It was further found that peer group influence and reading skills were positively correlated. Which means that children of higher abilities can challenge other children development and achievements. This supported the views of Adeyeni TO.$^{21}$ and Henry \& Rickman. ${ }^{22}$ that peer group has a significant influence on children's language development.

\section{Recommendations}

Based on the above findings, the study recommends:

1. School administrators and teachers should:

i. Adopt teaching/learning methods that are flexible enough to ensure that each child's potentials are easily harnessed.

ii. Establish reasonable linkages between school curriculum and private/personal learning initiatives at home.

iii. Provide stimulating classroom environment to enhance early reading skills.

2. Parents should among other things:

i. Re-orient their awareness and opinion on the importance of early inculcation of life-long learning skills as being foundational to other academic pursuits of the growing child. ii. Consciously take steps that encourage the clear definition of play time and study time at home.

iii. Concerted efforts by leaders at home and in school towards exemplifying productive use of leisure time and encouraging priority attention to be put on acquiring sustainable lifelong learning skills.

iv. Engage older siblings to serve as mentors to those in the early ages towards showcasing excellent reading achievements.

\section{Acknowledgments}

None.

\section{Conflicts of interest}

The authors declare no conflicts of interest.

\section{References}

1. Alava MH, Polpi G. Children's development and parental input: evidence from the UK MIllennium Cohort Study. Demography. 2017;54(2):485511.

2. Allen DE, Donham RS, Bernhardt SA. Problem-based learning. new directions for teaching and learning. 2011;21-29.

3. Cunha F, Heckman JJ. Formulating, identifying and estimating the technology of cognitive and noncognitive skill formation. Journal of Human Resources. 2008;43(4):738-782.

4. Frankenburg W. Developmental surveillance and screening of infants and young children. Pediatrics. 2002;109(1):144-145.

5. Awopetu AV. Effectiveness of mother tongue on children's learning abilities in early childhood classroom. Procedia - Social and Behavioral Sciences. 2016;233:58-63.

6. Adi-Japha E, Klein PS. Relations between parenting quality and cognitive performance of children experiencing varying amounts of childcare. Child Development. 2009;80(3):893-906.

7. Son SH,Morrison FJ.The nature and impact of changes in home learning environment on development of language and academic skills in preschool children. Developmental Psychology. 2010;46(5):1103-1118.

8. Weinert S, Ebert S, Dubowy M. Kompetenzen und soziale disparitäten im vorschulalter [Competencies and social disparities at preschool age]. Zeitschrift für Grundschulforschung. 2010;1:32-4.

9. Ashiabi GS. Play in the preschool classroom: its socioemotional significance and the teacher's role in play. Early Childhood Education Journal. 2007;35 (2):23-41.

10. Sammons P, Elliot K, Sylva K, et al. The impact of pre-school on young children's cognitive attainment at entry to reception. British Educational Research Journal. 2004;30:691-712.

11. Barros RMJ, Silver EJ, Stein RE. School recess and group classroom behavior. Pediatrics. 2009;123(2):34-50.

12. Zigler EF, Bishop SJ. The cognitive child versus the whole child: Lessons from forty years of head start. In: Singer DG, Golinkoff RM, editors. learning: How play motivates and enhances cognitive and socialemotional growth. New York: Oxford University Press; 2006:15-35.

13. Ossai OOV. The challenges of promoting reading culture in Nigerian children through story hour, book talks and exhibition: a case study of selected secondary schools in Owerri, Imo state, Nigeria. Library Philosophy and Practice (ejournal). 2012;877.

14. Eyo W. Nigeria: libraries and reading culture. Journal on the Culture of Reading and the Book Chain. 2007;6(1):17-25 
15. Akindele N. Reading culture, parental involvement and children's development in formative years: The covenant university experience. Library Philosophy and Practice (e-journal); 2012:805

16. Igwe KW. Reading culture and Nigeria's quest for sustainable development. Library Philosophy and Practice. 2011;7:34-41.

17. Haugland SW. Early childhood classrooms in the 21 st century: using computers to maximize learning. Young children. 2000;55(1):12-18.

18. Bornstein MH, Bradley RH. Socio-economic status, parenting, and child development. Mahwah, NJ: Erlbaum; 2008.

19. Anders Y, Sammons P, Taggart B, et al. The influence of child, family, home factors and pre-school education on the identification of special educational needs at age 10. British Educational Research Journal. 2011;37(3):421-441.
20. Burchinal M, Vandergrift N, Pianta R, et al. Threshold analysis of association between child care quality and child outcomes for low income children in pre- kindergarten programs. Early Childhood Research Quarterly. 2010;25(2):166-176.

21. Adeyeni, TO. The school library and students' learning outcomes in Ekiti state, Nigeria. Asia-Journal of business management. 2010;2(I):1-8.

22. Henry GT, Rickman DK. Do peers nfluence children's s kills development in pre-school?. Economics of Education Review. 2006;26(1):100-112. 